\title{
Twin pregnancy chorionicity determination in a tertiary care setting
}

\author{
T Dias ${ }^{1}$, A Weerasinghe ${ }^{2}$, P Amarathunga ${ }^{2}$, C De Silva ${ }^{2}$, B Thilaganathan ${ }^{1}$ \\ (Index words: chorionicity, twins, ante-natal ultrasound)
}

\begin{abstract}
Summary
Ultrasound determination of chorionicity is most reliable before 14 weeks and subsequently reduces in accuracy with advancing gestation. The aim of this study was to evaluate the accuracy of chorionicity determination in a birth cohort of twin pregnancies. Antenatal ultrasound determination of chorionicity in twin pregnancy was undertaken at suboptimal period of gestation in over twothirds of twin pregnancies. Even in the first trimester of pregnancy, the accuracy of chorionicity determination was lower than previously reported.
\end{abstract}

Ceylon Medical Journal 2013; 58: 170-2

\section{Introduction}

Outcome of twin pregnancy is mainly determined by the chorionicity. Monochorionic (MC) twins account for $20 \%$ of all spontaneous twin pregnancies, but the perinatal morbidity and mortality is five times higher than in dichorionic (DC) twins [1,2]. Fetal loss in monochorionic twins is mainly due to twin to twin transfusion syndrome (TTTS) and selective fetal growth restriction (sFGR) [3]. These two complications develop during early gestation, around 15-17 weeks, and fetal death occurs by 25 weeks if left untreated [2]. Women with monochorionic twin pregnancies therefore need more frequent contact with healthcare professionals and specialized care by a multidisciplinary team [4].

The National Institute of Clinical Excellence (NICE) has recently recommended offering women with multiple pregnancies a first trimester ultrasound scan to estimate gestational age, and to determine chorionicity [4]. The NICE guidelines also suggest a second option if chorionicity determination is not possible by ultrasound at the time of detecting the multiple pregnancy, and management of the pregnancy as monochorionic until proven otherwise if it is difficult to determine chorionicity [4]. The aim of this study was to evaluate the accuracy of routine monochrorionicity determination in a large cohort of twin pregnancies.

\section{Methods}

This retrospective observational study was carried out at the De Soysa and Castle Street Hospitals for Women, Colombo between 2009 and 2011. All consecutive twin pregnancies were recruited at the time of delivery and the earliest ultrasound record on chorionicity was reviewed to ascertain chorionicity data. Twin pregnancies without ultrasound and confirmatory chorionicity data were excluded. Twin placentas from respective labour rooms or theatres were collected at the time of delivery of twins and analyzed at the Department of Pathology at the Faculty of Medicine, Colombo.

Ultrasound scans were performed according to until protocols either by consultants or postgraduate trainees or Senior House Officers. The pregnancies were considered monochorionic in the presence of the T-sign and dichorionic with the $\lambda$-sign or when two separate placental masses were present during first trimester (Figure 1) [5].
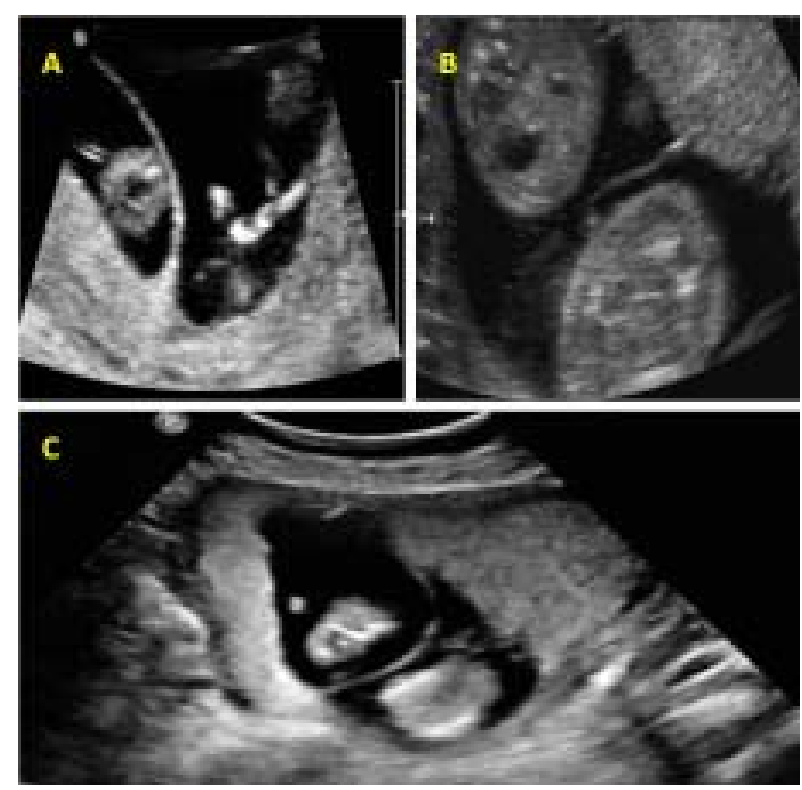

Figure 1. Ultrasound determination of chorionicity during first trimester (A: Lambda sign, B: T-sign, C: Two different placental masses.

${ }^{1}$ Foetal Medicine Unit, St George's University of London, London, United Kingdom, ${ }^{2}$ Faculty of Medicine, University of Colombo, Sri Lanka.

Correspondence: TD, e-mail: <thiran_dias@yahoo.com>. Received 20 March 2013 and revised version accepted 16 June 2013. Competing interests: none declared. 
Composite parameters of membrane thickness, discordant sex and first trimester markers were considered during second and third trimesters.

Chorionicity was confirmed by discordant sex at birth (dichorionic) or from placental histology. Ultrasound and chorionicity confirmation data were entered in a purpose designed Microsoft Excel data sheet. The sensitivity, specificity and the overall accuracy of antenatal determination of monochrorionicity were calculated. Ethical approval was obtained from the Ethics Review Committee of the Faculty of Medicine, University of Colombo.

\section{Results}

A total of 246 twin pregnancies were recruited during the study period. Thirty six twin pregnancies were excluded due to non availability of ultrasound chorionicity data $(n=15)$ or lack of chorionicity confirmatory data $(n=21)$. Patient characteristics are given in Table 1. Mean gestational age at first scan was 19 weeks (SD 7.3). There were 66 monochorionic twins and 144 dichorionic twins. There was no significant difference in the gestational age at assessment between monochorionic and dichorionic pregnancies $(p=1.00)$. The accuracy data for the determination of chorionicity for each trimester is shown in

Table 2 .

\section{Discussion} determine the accuracy of ultrasound chorionicity in each trimester. The overall accuracy of chorionicity determination was unacceptably low in all three trimesters. Given that $80 \%$ of twins were dichorionic, the overall accuracy of chorionicity $(<80 \%)$ seems not very different
This was the largest study carried out in Sri Lanka to

$$
\text { accuracy of chorionicity }(<80 \%) \text { seems not very different }
$$

to that would be achieved by random assignment. Even though it has been possible to determine chorionicity very accurately ( $>99 \%)$ as early as 11-14 weeks, the antenatal determination of chorionicity by ultrasound is not standard practice in Sri Lanka [5]. There are two main reasons for this, first being lack of uniformity in timing of first scan and secondly, lack of ultrasound training in chorionicity determination among obstetrics care givers.

\section{Table 1. Factor loadings of individual items after Varimax rotation}

\begin{tabular}{|c|c|}
\hline \multicolumn{2}{|l|}{ Hospital } \\
\hline - De Soysa Hospital for Women & 86 \\
\hline - Castle Street Hospital & 124 \\
\hline Mean maternal age (years, range) & $29.5(18-39)$ \\
\hline \multicolumn{2}{|l|}{ Parity } \\
\hline - Nulliparous & 55 \\
\hline - Multiparous & 155 \\
\hline \multicolumn{2}{|l|}{ Timing of first ultrasound scan (weeks) } \\
\hline - $11-14$ & $56(27 \%)$ \\
\hline - $14-28$ & $130(62 \%)$ \\
\hline - $>28$ & $24(11 \%)$ \\
\hline \multicolumn{2}{|l|}{ Modal time of delivery in weeks } \\
\hline - Monochorionic (66) & 37 \\
\hline - Dichorionic (144) & 37 \\
\hline \multicolumn{2}{|l|}{ Chorionicity confirmation } \\
\hline - Discordant sex & 76 \\
\hline - Placental histology & 134 \\
\hline
\end{tabular}

Table 2. Accuracy of determination of chorionicity in each trimester

\begin{tabular}{|c|c|c|c|c|c|c|}
\hline & & \multicolumn{5}{|c|}{ Confirmatory test (placental histology, discordant sex) } \\
\hline & & $\begin{array}{c}6^{+0} \text { to } 13^{+6}-56 \text { cases } \\
\text { (First trimester) }\end{array}$ & \multicolumn{2}{|c|}{$\begin{array}{c}14^{+0} \text { to } 28^{+6}-130 \text { cases } \\
\text { (Second trimester) }\end{array}$} & \multicolumn{2}{|c|}{$\begin{array}{c}28^{+0} \text { to } 35^{+6}-24 \text { cases } \\
\text { (Third trimester) }\end{array}$} \\
\hline & & $\mathrm{MC}$ & $\mathrm{MC}$ & $\mathrm{DC}$ & $\mathrm{MC}$ & $\mathrm{DC}$ \\
\hline Ultrasound & $\mathrm{MC}$ & 14 & 30 & 19 & 6 & 8 \\
\hline screening & $\mathrm{DC}$ & 32 & 9 & 72 & 3 & 7 \\
\hline Sensitivity & & $77.77 \%$ & \multicolumn{2}{|c|}{$76.92 \%$} & \multicolumn{2}{|c|}{$66.66 \%$} \\
\hline Specificity & & $84.21 \%$ & \multicolumn{2}{|c|}{$79.12 \%$} & \multicolumn{2}{|c|}{$46.66 \%$} \\
\hline PPV & & $70.00 \%$ & \multicolumn{2}{|c|}{$61.22 \%$} & \multicolumn{2}{|c|}{$42.85 \%$} \\
\hline NPV & & $88.88 \%$ & \multicolumn{2}{|c|}{$88.88 \%$} & \multicolumn{2}{|c|}{$70.00 \%$} \\
\hline Accuracy & & $82.14 \%$ & \multicolumn{2}{|c|}{$77.86 \%$} & \multicolumn{2}{|c|}{$54.16 \%$} \\
\hline
\end{tabular}


It is standard practice in most counties to offer the first routine scan between 11 and 14 weeks for pregnancy dating, chorionicity determination and Down syndrome screening $[4,5,6]$. According to this study, chorionicity was determined before 14 weeks only in $27 \%$ of twin pregnancies. As schedule of timing of ultrasound scans is not specified in antenatal policy, health care workers cannot be held responsible for the lack of uniformity in the timing of first scan. Sri Lanka is known for its well organized antenatal care with $99 \%$ coverage of the whole country [7]. More than $89 \%$ of mothers are booked by a midwife before the completion of the 12th week of gestation [7]. Recent reports state that the first scan can be scheduled during the first trimester even in peripheral units [8]. Considering the above, it is feasible to recommend the first antenatal scan before 14 weeks in the national antenatal policy. Given the incidence of twins of $2 \%$ and total of around 350,000 pregnancies per year in Sri Lanka, there would be nearly 7000 twin pregnancy deliveries each year [9]. As overall incidence of monochorionic twins' accounts for $20 \%$ of all twins, nearly 1400 monochorionic twins are delivered each year in Sri Lanka. If the first antenatal scan could be performed before 14 weeks, nearly 560 monochorionic babies per year could be saved by timely intervention for TTTS and SFGR, which are known early complications of MC twins.

It is appears that the present skill level in obstetric ultrasound is poor and it can be improved by training [10]. A systematic approach is needed in planning, training and auditing of obstetrics ultrasound skills.

\section{Conclusions}

Although the high accuracy of ultrasound determination of chorionicity has been consistently reported, the current data fails to meet that expectation. Carrying out the first ultrasound scan after the first trimester in over $70 \%$ of the cases is an important reason for the low accuracy. Furthermore, accuracy was poor even when first trimester scans were undertaken, suggesting that regular training and audit of ultrasound practice is important in optimizing diagnostic accuracy. Health care policy makers should consider these facts and national antenatal policy should be revised to introduce the first scan before 14 weeks.

\section{References}

1. Dias T, Bhide A, Thilaganathan B. Early pregnancy growth and pregnancy outcome in twin pregnancies. Ceylon Medical Journal 2010; 55: 80-4.

2. D'Antonio F, Khalil A, Dias T, Thilaganathan B. Southwest Thames Obstetric Research Collaborative (STORK). Early fetal loss in monochorionic and dichorionic twin pregnancies: analysis of the the Southwest Thames Obstetric Research Collaborative (STORK) multiple pregnancy cohort. Ultrasound in Obstetrics and Gynecology 2013; 41: 632-6.

3. Memmo A, Dias T, Mahsud-Dornan S, et al. Prediction of selective fetal growth restriction and twin-totwin transfusion syndrome in monochorionic twins. British Journal of Obstetrics and Gynaecology 2012; 119: 417-21.

4. National Institute for Health and Clinical Excellence. [Multiple pregnancy: The management of twin and triplet pregnancies in the antenatal period]. [CG129]. National Institute for Health and Clinical Excellence, London, UK, 2011.

5. Dias T, Arcangeli T, Bhide A, et al. First-trimester ultrasound determination of chorionicity in twin pregnancy. Ultrasound in Obstetrics and Gynecology 2011; 38: 530-2.

6. Dias T, Mahsud-Dornan S, Thilaganathan B, et al. Firsttrimester ultrasound dating of twin pregnancy: are singleton charts reliable? British Journal of Obstetrics and Gynaecology 2010; 117: 979-84.

7. Senanayake H, Goonewardene M, Ranatunga A, et al. Achieving Millennium Development Goals 4 and 5 in Sri Lanka. British Journal of Obstetrics and Gynaecology 2011; 118 Suppl 2: 78-87.

8. Gunawardane BANP, Kumarasiri SG, Wanigasekara RV, et al. The dating scan - Is pragmatic in Sri Lanka? Presented at the Annual Scientific Sessions of the Perinatal Society of Sri Lanka, June 22, 2012, Colombo.

9. Family Health Bureau, Ministry of Healthcare and Nutrition. Annual Report on Family Health 2006-2007. Family Health Bureau, Ministry of Healthcare and Nutrition: Sri Lanka, 2009.

10. Dias T, Ruwanpura L. Systematic introduction of obstetric ultrasound skills into practice. Sri Lanka Journal of Obstetrics and Gynaecology 2011; 33: 154-7. 